\title{
A UNIVERSIDADE ESTADUAL DO OESTE DO PARANÁ E SEU CONTEXTO SÓCIO-HISTÓRICO
}

\author{
Paulino José Orso ${ }^{1}$
}

\section{RESUMO:}

Este artigo apresenta uma breve história da Universidade Estadual do Oeste do Paraná UNIOESTE -, partindo de sua localização e contextualização sócio-histórica, passando pela sua trajetória, pelos desafios de sua consolidação, pela articulação entre o ensino, a pesquisa e a extensão, bem como pela importância dos grupos de pesquisa perante estas três dimensões da universidade.

Palavras-chave: História das Instituições Escolares; Universidade; Unioeste

\section{THE STATE UNIVERSITY OF THE WEST OF THE PARANÁ AND ITS CONTEXT SÓCIO-HISTÓRICO}

\begin{abstract}
:
This article presents one brief history of the State University of the West of the Paraná UNIOESTE -, breaking of its localization and partner-historical contextualização, passing for its trajectory, the challenges of its consolidation, for the joint between education, the research and the extension, as well as for the importance of the groups of research before these three dimensions of the university.
\end{abstract}

Keywords: History of School Institutions; University; Unioeste

\section{Localização e contexto sócio-histórico da Unioeste}

Quando se trata de analisar algo concreto, como é o caso de uma Instituição de Ensino Superior, a abordagem de aspectos sócio-históricos torna-se praticamente indispensável, uma vez que, ela não se explica por si. As relações históricas e sociais nas quais encontra-se inserida contribuem significativamente para auxiliar na sua compreensão. Por isso, far-se-á uma breve contextualização da Região Oeste do Paraná, onde situa-se a Unioeste, para em seguida tecer considerações sobre suas especificidades enquanto instituição universitária.

Da mesma forma que a universidade não se explica por si só, o presente também não é suficiente para explicá-la de forma cabal. Parte do que somos deve-se ao nosso passado, ao tipo de colonização, ao processo de desenvolvimento aqui implantado, que se explica não apenas e simplesmente descrevendo o que ocorre no momento, mas sim pela etapa de desenvolvimento local, articulado à etapa de desenvolvimento e as relações mais amplas travadas na sociedade brasileira e até mesmo, pelas raízes culturais que para cá foram "transplantadas".

Como é de conhecimento geral, a cultura e civilização brasileiras têm suas raízes no velho mundo, principalmente, nos países ibéricos. Neste sentido, Florestan Fernandes é enfático ao afirmar que o Brasil é produto da 
'expansão da civilização ocidental', isto é, de um tipo moderno de colonialismo organizado e sistemático. Esse colonialismo teve seu início com a 'conquista' - espanhola e portuguesa - e adquiriu uma forma mais complexa após a emancipação nacional ${ }^{2}$.

Após a chegada dos colonizadores europeus ao continente americano, tanto para os habitantes que aqui viviam como para os que aqui aportaram, iniciou-se uma nova jornada. Os padrões culturais europeus foram trazidos juntos com os colonizadores para as colônias. A dominação colonial adquiriu um caráter de exploração ilimitada em todos os níveis da existência e da produção.

A exploração não se limitou aos nativos americanos, nem aos africanos que foram caçados, apereados em suas terras de origem e trazidos para cá, submetidos ao trabalho forçado. A exploração foi estendida a todos os desprovidos de propriedade, cuja garantia de existência, depende da alienação da força de trabalho. A dominação imposta pelos colonizadores passou a ser organizada dentro do próprio sistema e exercida por uma classe, uma raça, um determinado estamento sobre outro, de forma que tornou-se contínua e extensiva ao conjunto da sociedade.

Assim, instituiu-se uma "organização aristocrática, oligárquica e plutocrática da sociedade que sempre concentrou extremamente a riqueza, o prestígio social e o poder em alguns estratos privilegiados"3. E, apesar de que o Oeste do Paraná tenha sido colonizado "tardiamente", não tem sido diferente.

A Universidade Estadual do Oeste do Paraná - UNIOESTE - constitui-se numa Instituição de Ensino Superior - IES - multi-campi, tendo sua sede - reitoria - no Campus de Cascavel. Além deste, também conta com outros 3 campis situados em Toledo, Marechal Cândido Rondon, Foz do Iguaçu, no Oeste do Paraná e um em Francisco Beltrão, no Sudoeste do estado, e três extensões: Santa Helena, Palotina e Medianeira, também na Região Oeste do Paraná, divisando com o Paraguai e Argentina.

Se comparadas às demais regiões do país, pode-se dizer que estas são de colonização bastante recente. Um longo período de permanência e o desenvolvimento de uma economia predatória, aliada às crises geradas pelas demarcações de fronteiras e os freqüentes conflitos internos retardaram sua ocupação e colonização.

O Oeste Paranaense, por exemplo, só foi ocupado efetivamente entre os anos de 1940 e 1970, sendo marcado direta e imediatamente pelo impacto provocado pelas profundas transformações sociais, científicas e tecnológicas que ocorriam nesse momento no país, aliadas ao modo de produção capitalista e a ausência de consciência sobre as possíveis consequiências futuras que isso poderia provocar. Antes de ocorrer a colonização propriamente dita, a região era ocupada por índios, principalmente da tribo dos guaranis. Mas, como nas demais regiões do Brasil, a primeira preocupação dos colonizadores foi com a posse da terra e, em decorrência da lógica mercadológica, com os resultados imediatos e com os lucros fáceis.

Em função disso, as tentativas de colonização provocaram a perseguição, escravização e morte de muitos povos nativos. Outros, devido a essas perseguições, para garantir a sobrevivência, foram forçados a fugir para a Região dos Sete Povos das Missões no Rio Grande do Sul, para o Uruguai e Paraguai. Ou seja, os processos de ocupação e colonização do Oeste do Paraná, além de um rastro de destruição predatória do meio ambiente, também provocaram uma vaga de destruição sócio-cultural.

Inicialmente a economia era baseada no extrativismo vegetal, principalmente da erva mate. Depois, favorecida por solos férteis e planos, a produção agrícola assumiu a primazia. Mais recentemente, por um lado, os latifúndios e o agro-negócio assumem o domínio da produção agrícola e, por outro, em função do êxodo rural e do aumento da 
urbanização, desenvolve-se o comércio, com um lento processo de industrialização. E, em decorrência disso, no final do século XX e início do XXI, ocorre uma rápida expansão do ensino superior privado.

“Após o reconhecimento da Universidade Estadual do Oeste do
Paraná (UNIOESTE), como estadual, em 1994, em 1995 foi criada
a primeira instituição privada, com incentivos da Prefeitura
Municipal (...). No ano de 1999, como que para 'coroar' a
tendência da década de 90, foram criadas 4 instituições privadas,
sendo um campi de universidade (UNIPAR) e uma faculdade
filantrópica (FAG) (...). Recentemente, nos anos de 2004 e 2005 ,
foram criadas 3 instituições, com cursos que visam uma parcela do
'mercado' ainda não atingida pelas instituições já existentes. Trata-
se dos cursos de Teologia, da Faculdade Missioneira do Paraná
(FAMIPAR), de Assistência Social, da Faculdade Harpa de
Cascavel, que não existiam no município e de 4 cursos
tecnológicos (com duração de dois anos) e um de administração, da
Faculdade Alfa Brasil (FAAB). Estas instituições oferecem apenas
estes cursos e surgiram a partir de outras instituições existentes:
Arquidiocese de Cascavel, Curso Harpa Idiomas e Colégio Alfa,
respectivamente"4.

Neste momento, porém, não vamos nos deter aqui sobre o crescimento do ensino superior privado na região. Entretanto, pode-se afirmar que a expansão desse setor não foi muito diferente do verificado em cascavel, respeitadas as condições e o tamanho das cidades. Aliás, apesar de a colonização do Oeste do Paraná ter sido praticamente a última fronteira a ser realizada no Brasil, a expansão do Ensino Superior tem acompanhado a forma e o momento em que também ocorreu no restante do país.

Veja-se, porém, que entre 1994 e 2005, foram criadas 10 instituições privadas. Em razão dos fatos mencionados anteriormente, a ocupação e a efetiva colonização da Região Oeste do Paraná, da mesma forma que a época e as condições de desenvolvimento assumiram características bastante peculiares.

A ocupação efetiva desta região foi realizada por colonos vindo do Norte e do Sudoeste do Paraná e, mais tarde, por colonos italianos e alemães procedentes do Norte do Rio Grande do Sul e Oeste de Santa Catarina. Todavia, uma vez superadas as principais barreiras e entraves, a transformação e o crescimento ocorreram rapidamente, como se pode perceber por estes dados: em 1950 a população já atingia 34.193 habitantes, pulando em 1960, para 172.928. Na Região Oeste, favorecida por sua posição geográfica e econômica, Cascavel, sede da Unioeste, impõe-se politicamente sobre as demais. Segundo o IBGE, em 2007, sua população aproxima-se dos 300.000 habitantes. Como vimos, à medida que foi aumentando a produção, cresceu a população e a economia se inseriu no contexto nacional e internacional trazendo junto o êxodo rural, além de provocar as conseqüências típicas dos processos de desenraizamento dessas grandes massas e a integração em um ambiente que lhes era estranho. Com isso, agravam-se a violência, a precarização das condições de vida de um grande número de pessoas que são jogadas para o desemprego, subemprego, o trabalho informal e para o tráfico para tentar garantir sua sobrevivência.

No Oeste do Paraná, cuja economia baseia-se principalmente na agricultura, as relações sociais sempre foram muito marcadas pela mentalidade rural. Ao contrário dos 
grandes centros, onde as relações sociais parecem ser mais impessoais, marcadas pelo distanciamento, elas ainda carregam fortes traços de familiaridade, típico de uma mentalidade agrária. O mandonismos, o personalismo, o homem aventureiro, apontados por Sérgio Buarque do Holanda ${ }^{5}$ e o patrimonialismo, destacado por Raymundo Faoro ${ }^{6}$, herdados do passado, de nossos colonizadores, continuam ainda muito presentes. Muitas vezes as lutas, os conflitos e disputas são resolvidas diretamente, por meio da força bruta, na luta pessoal e não mediadas pela burocracia burguesa.

O Oeste do Paraná tem representado uma força econômica muito forte no Estado. Todavia, foi pela alternativa do associativismo que os colonos tiveram que resolver seus problemas e desafios educacionais, visto que "a política paranaense, até a década de 1960, sempre foi, de diferentes formas, ligada aos interesses das oligarquias do chamado Paraná tradicional, que administravam a Província e o Estado para si" ". Contudo, o associativismo também não foi suficientemente forte e capaz de garantir os "benefícios" do Estado para a região.

À medida em que aumentava a produção, crescia a população e a economia inseria-se no contexto nacional, conforme o êxodo rural ia crescendo, ampliavam-se e complexificavam-se as relações sociais. Devido ao impacto gerado pela mecanização das lavouras, cresciam as vilas e núcleos municipais; as propriedades rurais concentravam-se e o poder político local e estadual deslocava-se para as mãos de outros grupos sociais: comerciantes, industriais e banqueiros, espécie diferentes de oligarquias estabeleciam o domínio fechadas em si mesmas, ciosas de poder local, regional e nacional. Estas mantiveram uma mentalidade conservadora, avessa e resistente até mesmo às transformações e à modernização capitalista. O poder político, o espaço público e as instituições passaram a refletir mais explicitamente o jogo de focas e os interesses destes grupos.

Assim, de uma região eminentemente rural no passado, com os processos de desenvolvimento e com a inserção da tecnologia no campo, hoje predomina a urbanização e o comércio, trazendo junto novos desafios. Em termos de municípios a Região Oeste conta com 50 e a Região Sudoeste com outros 37. Neste contexto, a escola tem sido uma das primeiras e principais preocupações e a educação tem se constituído num importante fator de lutas e mobilizações sociais, e, razão de que o processo de ocupação dessa região ocorre num momento em que a educação formal já se encontrava bastante difundida também no Brasil e passa a ser compreendida como um importante instrumento de coesão, crescimento e integração social.

\section{Trajetória Histórica da Unioeste}

O Ensino Superior, nestas regiões, está diretamente ligado à forma de colonização e desenvolvimento. Desde o seu início a universidade constitui-se como parte do processo histórico. Com as rápidas transformações ocorridas na região, a ausência de um bom nível de escolaridade representava insegurança no trabalho e dificultava a ascensão social.

Tendo isso presente, na década de 1970, os centros urbanos mais desenvolvidos da região (Cascavel, Toledo, Marechal Cândido Rondon e Foz do Iguaçu) sentiram a necessidade de, a partir de seu próprio processo de desenvolvimento, ampliar as condições e os níveis de escolaridade, evitando que os estudantes tivessem que se deslocar para outras regiões e estados para realizar sua formação superior.

Desse modo, em 1972 é criada a Faculdade de Cascavel - Fecivel -, em 1979 a 
Faculdade de Foz do Iguaçu - Facisa -, em 1980 as faculdades de Toledo - Facitol - e a de Marechal Cândido Rondon - Facimar. Em 1986 intensificaram-se as mobilizações com o objetivo de se criar uma universidade no Oeste do Paraná. E, em decorrência disso, em 1988, é criada a Fundação Universidade do Oeste. Paralelamente a isso, internamente promoveu-se um programa de incentivo à qualificação e titulação dos docentes visando a consolidação das condições para a transformação em Universidade. Assim, depois de um intenso trabalho, de muitas lutas e mobilizações, em 23 de dezembro de 1994, a Universidade Estadual do Oeste do Paraná obteve o reconhecimento do MEC como Universidade Multi-Campi e, no ano 2000, a Facibel, faculdade de Francisco Beltrão, também é incorporada à Unioeste.

Apesar de sua ainda curta trajetória, diuturnamente a Unioeste vem conquistando espaços e se destacando junto à comunidade científica e extra-acadêmica em função dos esforços que vem realizando junto ao ensino, à pesquisa e à extensão, muitas vezes, a despeito de não ter as melhores condições de trabalho e, sobretudo, apesar dos constantes cortes de orçamento e do achatamento dos salários de seus docentes e funcionários. Mesmo nestas condições, algumas de suas pesquisas já têm conquistado destaque nacional e até internacional; as atividades de extensão têm sido significativas, sendo reconhecidas pela comunidade regional; em termos de ensino, as avaliações do tipo Provão, nos últimos anos têm apontado a Unioeste como uma das importantes e melhores instituições de ensino superior do país. Também merece destaque o fato de um de nossos colegas professores, o professor André Paulo Castanha ter defendido sua tese de doutorado e ter conquistado o Prêmio de Melhor Tese do ano (2008) na área de educação.

Atualmente (2008), ela conta com 5 campis, mais de 11.000 alunos entre graduação e pós-graduação, aproximadamente 1.100 funcionários e cerca de 1.200 docentes concursados e contratados, distribuídos por 16 centros, 34 cursos de graduação que integram 63 turmas de alunos. Além disso, também obteve a recomendação da CAPES para a instauração de 10 cursos de mestrado e 2 de doutorado o que, de acordo com a legislação, lhe garante o estatuto de Universidade.

Em 2008, a UNIOESTE conta, mais especificamente, com 1148 docentes. Destes, 18 ou então, 1,6\% são pós-doutores, 340 ou seja, 29,6\% são doutores, 541 ou seja 47,1\% são mestres, 186 ou 16,2\% são especialistas e apenas 63 ou seja 5,5\% são graduados. Além destes, outros 126 encontram-se em fase de qualificação. Isto significa que a instituição tem quase $80 \%$ de seus docentes com título de mestrado, doutorado e pósdoutorado.

\section{Desafios de sua consolidação}

Consolidada sua expansão horizontal, a política traçada pelo Plano de Desenvolvimento Institucional - PDI - estabelece como prioridade à verticalização. A elevação da titulação dos docentes também tem resultando num processo de aprimoramento da capacidade de pesquisa, investigação e produção de novos conhecimentos, além de contribuir com o desenvolvimento regional. Entretanto, apesar de seu potencial, também apresenta algumas fragilidades que, uma vez superadas, poderiam potencializar ainda mais seu processo de crescimento, desenvolvimento e consolidação.

Por exemplo, até o momento a instituição ainda não possui um banco de dados que se possa, rapidamente, localizar e visualizar toda a produção científica da instituição, nem sobre a educação regional, para que possa torná-la acessível e disponibilizada à 
comunidade. Isto, porém, não demandaria de muitos recursos para realizar. Contudo, essa carência impossibilita uma visibilidade sobre os rumos percorridos pela Unioeste até o momento, bem como, não permite vislumbrar os caminhos por onde se está percorrendo, nem as possíveis tendências que estão sendo indicadas, de tal forma que dê para traçar sérias, efetivas e consequientes propostas em relação à comunidade local, regional e nacional. Na ausência disso, não se tem uma definição sobre as prioridades e as principais exigências e demandas. Também não se consegue avaliar até que ponto a produção de conhecimento, as pesquisas vão correspondendo ao processo de transformação que vai ocorrendo na região, nem verificar se caminham juntos ou de forma descompassada.

Entretanto, em sua curta trajetória enquanto uma Universidade reconhecida, já deu significativos passos em seu processo de consolidação real. Os números relativos ao crescimento de cursos, docentes, técnicos administrativos, bem como, a verticalização com a oferta de muitos cursos de especialização lato sensu e stricto sensu a nível de mestrado e doutorado, aliada às pesquisas e à extensão, revela, não apenas seu crescimento rápido, mas sua consolidação junto à comunidade regional.

Todavia, essa realidade também evidencia outra fragilidade, que compromete um progresso ainda maior, que é a falta de maior investimento por parte do governo do estado e a falta de autonomia da instituição. Isto, porém, não é uma exceção da Unioeste. As IES consideradas públicas, em geral, têm sofrido cortes assemelhados e ingerência por parte dos políticos de plantão. Inúmeras são as formas de privatizar o conhecimento e a educação. Quer seja através da institucionalização da Prestação de Serviços, das Parcerias Público Privadas, da compra de vagas nas instituições privadas ou por meio do controle por parte dos políticos que, em função do cargo que ocupam, outorgam-se o direito de fazer da universidade como se fosse seu patrimônio, confundem a instituição pública com uma gerência doméstica.

Dentro desta perspectiva, a educação também adquire a marca da sociedade privada e transforma-se em mercadoria. Senão vejamos. Como o Estado é um Estado de classe, não é uma instância neutra, quais são os projetos de pesquisa que são aprovados e financiados? Em sendo as Instituições consideradas públicas, geralmente de melhor qualidade, a concorrência para nelas ingressar é cada vez maior, fazendo com que, geralmente, o critério de seleção acabe sendo o econômico. Como os recursos para as universidades são cada vez mais escassos, como os salários são aviltados, grande parte dos profissionais que atuam nas instituições ditas públicas (estatais) transformam a universidade num bico, uma forma de garantir status e projetar-se junto ao mercado, às empresas, não assumindo compromisso efetivo com a instituição. Quando não, simplesmente, fazem concursos em outras instituições e pedem demissão.

Deste modo, ainda que se mantenha a denominação de pública, por diferentes formas, a universidade acaba assumindo um caráter cada vez mais privado, quer via seleção dos projetos que recebem recursos das agências financiadoras, quer através da prestação de serviços, tornando os profissionais, o conhecimento e as instituições reféns da iniciativa privada e do mercado. Ou seja, desta forma, ainda que as chamadas instituições "públicas", geralmente, sejam as que de fato mais e melhor realizem pesquisa, que tenham um nível e uma qualidade de ensino melhor, e que possibilitem uma maior socialização do conhecimento, a educação compreendida como ensino, pesquisa e extensão não é tão pública quanto parece e os produtos e a extensão da pesquisa, do ensino e da extensão não permitem que de fato, nesta sociedade, os denominemos de públicos.

Portanto, não basta a "quantidade" da produção, não é suficiente que a instituição 
seja chamada de pública, não é suficiente o mérito e o destaque nacional e até internacional. É preciso que a produção da vida material e a organização da vida social tornem possível a realização daquilo que de fato denominamos de público, ou seja, que de fato a Instituição de Ensino Superior atenda e volte-se aos interesses da sociedade como um todo. Entretanto, ainda que a união indissolúvel entre o ensino, a pesquisa e a extensão não sejam necessariamente garantia da qualidade do ensino, para que ela realmente ocorra, a articulação entre estas três dimensões é uma condição sine qua non para isso.

No caso da Unioeste, por um lado, significa que o crescimento real de investimentos não tem acompanhado par e passo, o crescimento do número de cursos, alunos e níveis de ensino. Por outro, significa que, se mesmo nestas condições, a universidade vem crescendo e se consolidado como um importante centro de produção e difusão do conhecimento científico, o mérito cabe aos seus docentes e funcionários que não medem esforços para realizar seu trabalho, nem se limitam à carga horária formal registrada em seus Planos Individuais de Atividades Docentes - PIAD.

Diante destas dificuldades e limites, muitos docentes obstinados procuram suprir tais deficiências, ampliando sua carga de trabalho ou então por meio de um sobretrabalho, organizam-se em grupos, racionalizam os investimentos, melhoram seus projetos. Este, por exemplo, é o caso do Grupo de Pesquisa em História, Sociedade e Educação no Brasil - GT da Região Oeste do Paraná - HISTEDOPR - que, aliando-se ao grupo nacional - HISTEDBR - vem empreendendo uma série de ações no campo do ensino, da pesquisa e da extensão, contribuindo assim, para melhor compreender a história e a realidade local e nacional.

Aliás, é comum ouvirmos falar que a Universidade está fundada em três pilares: o ensino, a pesquisa e a extensão, indissociáveis entre si e a própria Constituição Federal, em seu artigo 207, estabelece como princípio.

A despeito disso, na maioria das vezes, isto não passa de princípios formais. Contudo, pesquisa, ensino e extensão são os três mais importantes pilares das instituições universitárias que se prezam. A centralização ou a redução a apenas uma ou outra destas dimensões, no mínimo, representa uma fragilidade da própria instituição. Contudo, atualmente, isto não é tão raro acontecer como se suporia. Há, inclusive, um estímulo por parte dos próprios Organismos Internacionais e até dos próprios governos no sentido de reduzir a maioria das Instituições de Ensino Superior - IES - ao ensino. Aliás, não há IES sem ensino, no entanto, não é possível dizer o mesmo em relação à pesquisa e à extensão. Com a anuência dos órgãos oficiais, existem muitas instituições que, numa relação mercadológica, excluem a pesquisa e a extensão e limitam suas atividades ao ensino, claro que não sem prejuízos ao próprio ensino, mas não só, também para a sociedade. Neste caso, temos o conhecimento reduzido a negócio, ao útil, ao circunstancial, ao prático, ao momentâneo, senão ao cotidiano - uma pobreza total.

Sediado na Universidade Estadual do Oeste do Paraná, o HISTEDOPR, criado em 2002, atualmente conta com um significativo número de integrantes, entre alunos da graduação, da especialização em História da Educação Brasileira, do Mestrado em Educação, Mestres, doutores, pertencendo a quatro dos 5 campis da Unioeste e também da comunidade externa.

Atendendo ao princípio constitucional e educacional, em relação ao ensino, no caso do HISTEDOPR, desde que tem sido criado, vem procurando qualificá-lo por meio de sua articulação com a pesquisa, com a iniciação científica e com os grupos de estudos.

Criamos dois grupos de estudos, cada um com 40 alunos, um durante a semana e outro nos sábados, para estudar a obra de Marx e Engels, iniciando por ordem 
cronológica de sua publicação, percorrendo pelas principais obras até chegar a sua obra magna, $O$ Capital.

Junto com os grupos de estudos, também criamos um curso de especialização lato senso em História da Educação Brasileira, em que já concluímos a terceira turma e estamos organizando a quarta, que deve ser ofertada em Francisco Beltrão. Já foram defendidas aproximadamente 80 monografias, todas voltadas para a pesquisa e para a história social e educacional da Região Oeste do Paraná. Com isso, cremos estar dando uma importante contribuição para o projeto de levantamento e catalogação de fontes primárias e secundárias para a educação regional e nacional, permitindo, assim, compreender um pouco melhor a história da educação brasileira e, consequiêntemente, também a sociedade.

Em decorrência da realização do Curso de Especialização, das pesquisas e das monografias, também já organizamos quatro coletâneas com artigos sínteses das produções monográficas e, em 2011, deverá ser publicada mais uma obra. Estas obras compõe a coleção História, Sociedade e Educação, todas elas tendo o foco na História da Educação, na pesquisa, no levantamento de fontes, na preservação da história regional e nacional.

Em relação à extensão promovemos um Ciclo de Debates periódicos, no qual, ao todo, até 2010, já foram realizados 41 debates, envolvendo temas sociais e educacionais aberto aos alunos, professores e à comunidade em geral visando integrar a Pesquisa, o Ensino e a Extensão, articulando o Ensino Fundamental, o Médio, o Superior e a Comunidade extra-acadêmica. Com este intuito criamos um espaço acadêmico multi e interdisciplinar chamado genericamente de Ciclo de Debates, articulados ao qual foram realizados mensalmente durante três anos um total de 22 debates. Em 2006, a nomenclatura foi alterada para Jornada de estudos e pesquisas em História, Sociedade e Educação, por meio da qual foram realizados mais cinco debates. Cada evento versa sobre uma temática específica. Todos são abertos à comunidade acadêmica e extraacadêmica, tendo um caráter gratuito. Em 2008 realizaremos mais um Ciclo de Debates, com seis debates, sob a temática: Jornada de estudos e pesquisas em História, Sociedade e Educação: desafios da educação do nosso tempo, em que serão debatidos os seguintes temas: Rousseau: educação e política, A Educação no Brasil Império, O Positivismo e a educação pública no Brasil no século XIX, A educação e o processo de colonização do Oeste do Paraná, O primeiro grupo escolar da Região Oeste do Paraná, A História da Política Estadual Paranaense para o ensino médio e profissional do Governo Lerner.

No ano de 2009, foram realizados cinco debates sobre: A Universidade nos tempos modernos, Educação no Brasil Império, A educação e a cultura durante a ditadura, As políticas de educação e saúde, As políticas para a educação especial e, finalmente, em 2010, realizamos outros cinco debates, com as seguintes temáticas: Um estudo antropológico sobre a prostituição feminina, A contribuição de Paulo Freire para a educação brasileira, Políticas públicas para a população negra, A Universidade Brasileira: Componentes Ideológicos do PAIUB e seus desdobramentos na UNIOESTE,

Junto a estas atividades, estão sendo realizadas uma série de projetos de pesquisas individuais ou coletivos, assim como também submetemos diversos projetos aos órgãos financiadores, através dos quais conseguimos arregimentar uma estrutura mínima, básica para realizarmos nossas atividades.

Um destes projetos visa promover o levantamento, o resgate e a catalogação de toda produção acadêmica e científica dos docentes efetivos e também, se possível, dos docentes colaboradores da Unioeste, desenvolvida nos seus cursos de mestrado e doutorado, tornando-a acessível a toda comunidade, bem como, realizar o levantamento e 
a catalogação da produção da Escola Pública da Região Oeste do Oeste do Paraná entre 1940 e 1970.

Estes projetos particulares fazem parte de um projeto maior que vem sendo desenvolvido em âmbito nacional pelo Grupo de Pesquisa em História, Sociedade e Educação no Brasil - HISTEDBR -, coordenado pelo Prof. Dr. Dermeval Saviani, Emérito da Unicamp, constituído por 25 Grupos de Trabalho (GTs), espalhados por diversos estados e regiões do Brasil que têm como objetivo promover o levantamento e a catalogação de fontes primárias e secundárias para a História da Educação Brasileira.

Apesar de sua fragilidade, dadas às circunstâncias sociais, políticas e econômicas e dos interesses que a permeiam e que a cercam, a localização estratégica da Unioeste em relação aos países do Mercosul, bem como, o fato de estar situada nacionalmente num local, num entroncamento de fácil deslocamento tanto em relação à capital do Estado do Paraná, como aos estados do Sul, do Centro Oeste e também do Sudeste, indica que, superados os entraves momentâneos, ela tende a se afirmar enquanto uma importante instituição dinamizadora da cultura e do desenvolvimento social e humano e conquistar um lugar de destaque entre as melhores instituições do país.

Pode-se dizer que a Unioeste é uma síntese e resultado do processo histórico que a antecedeu. Em função disso, também se pode dizer que, sobre ela, pesa uma dívida sócio-histórica e ambiental. Ou seja, assim como a Instituição está assentada sobre os ombros da história, sobre um passado de lutas, de destruição e mortes, cabe a ela utilizar o conhecimento histórico e cientificamente acumulado para restabelecer o equilíbrio ambiental e garantir uma vida humana aos desterrados e aos que pagaram o preço pala construção da Universidade. Noutras palavras, cabe à Universidade agora cumprir seu compromisso social, contribuindo para a emancipação humana.

\section{BIBLIOGRAFIA}

MARTIN, Édison. A gênese da Faculdade de Filosofia, Ciências e Letras de Cascavel (1968-974). Cascavel: Unioeste, 2006. (Monografia do Curso de Especialização em História da Educação Brasileira).

EMER, Ivo Oss. Desenvolvimento do Oeste do Paraná e a Construção da Escola. Rio de Janeiro: Fundação Getúlio Vargas, 1991. Dissertação de Mestrado.

FAORO, Raymundo. Os Donos do Poder: formação do patronato brasileiro. Porto Alegre, Ed. Globo, $3^{\text {a }}$ edição, 1976.

FERNANDES, F. Capitalismo dependente e classes sociais na América Latina. Rio de Janeiro: Editora Zahar, 1973

HOLANDA, Sérgio Buarque. Raízes do Brasil. 16 edição, Rio de Janeiro: Livraria José Olympio Editora S.A., 19083.

ORSO, Paulino José. A concepção de poder em Michel Foucault e as relações de poder na Universidade Estadual do Oeste do Paraná - UNIOESTE. Campinas-SP: Unicamp, 1996. Dissertação de Mestrado.

Liberalismo, neoliberalismo e educação. Roque Spencer Maciel de Barros, um ideólogo da burguesia brasileira. Campinas: Unicamp, 2003. Tese de Doutorado. Vol. II.

A criação da universidade e o projeto burguês de educação no Brasil. In: Anais do VI Seminário Nacional de Estudos e Pesquisas do HISTEDBR. Campinas: FAE, 
2005.

PERES, Cláudio Afonso. O público e o privado na educação superior: o caso de Cascavel. Cascavel: Unioeste, 2006. (Monografia do Curso de Especialização em História da Educação Brasileira).

THOMÉ, Sérgio Antonio. A primeira Escola Primária em Cascavel. Cascavel: Unioeste, 2006. (Monografia do Curso de Especialização em História da Educação Brasileira).

SPERANÇA, Alceu A. Cascavel a história. Curitiba: lagarto, 1992.

SPERANÇA, Alceu A \& SPERANÇA, Carlos. Pequena história de Cascavel e do Oeste. Cascavel-PR: J. S. Impressora ltada, 1980.

Notas:

1 Doutor em História e Filosofia da Educação pela Unicamp, docente dos cursos de graduação em Pedagogia e do mestrado em Educação da Universidade Estadual do Oeste do Paraná e líder do Grupo de Pesquisa em História, Sociedade e Educação no Brasil - GT da Região Oeste do Paraná - HISTEDOPR.

2 FERNANDES, F. Capitalismo dependente e classes sociais na América Latina. Rio de Janeiro: Editora Zahar, 1973, p. 11.

${ }^{3}$ Idem, Ibidem.

${ }^{4}$ Para mais informações sobre o crescimento das instituições privadas no Oeste do Paraná, conferir PERES, Cláudio Afonso. O público e o privado na educação superior: o caso de Cascavel. Cascavel: Unioeste, 2006. (Monografia de Especialização em História da Educação Brasileira).

${ }^{5}$ Cf. HOLANDA, Sérgio Buarque. Raízes do Brasil. $16^{\mathrm{a}}$ edição, Rio de Janeiro: Livraria José Olympio Editora S.A., 19083.

${ }^{6}$ Cf. FAORO, Raymundo. Os Donos do Poder: formação do patronato brasileiro. Porto Alegre, Ed. Globo, $3^{\mathrm{a}}$ edição, 1976.

${ }^{7}$ EMER, Ivo Oss. Desenvolvimento Histórico do Oeste do Paraná e a Construção da Escola. Rio de Janeiro: FGV, 1991, p. 35. Dissertação de Mestrado.

Recebido em 23/02/2011

Aprovado em 30/03/2011 